\title{
Multifactorial analysis of risk factors for reduced bone mineral density among postmenopausal women
}

\author{
Grażyna Bączyk¹, Tomasz Opala², Paweł Kleka ${ }^{3}$, Marek Chuchracki
}

\author{
${ }^{1}$ Department of Nursing, Faculty of Health Sciences, Poznan University of Medical \\ Sciences, Poland \\ 2Department of Mother and Child Health, Faculty of Health Sciences, Poznan \\ University of Medical Sciences, Poland \\ 3Institute of Psychology, Adam Mickiewicz University, Poznan, Poland \\ Submitted: 12 July 2011 \\ Accepted: 1 November 2011
}

Arch Med Sci 2012; 8, 2: 332-341

DOI: 10.5114/aoms.2012.28562

Copyright $\odot 2012$ Termedia \& Banach

\author{
Corresponding author: \\ Grażyna Bączyk PhD \\ Department of Nursing \\ Faculty of Health Sciences \\ Poznan University \\ of Medical Sciences \\ 11 Smoluchowskiego \\ 60-179 Poznan, Poland \\ Phone: +48 616559261 \\ Fax: + 48616559266 \\ E-mail: gbaczyk@ump.edu.pl
}

\begin{abstract}
Introduction: The study aimed to determine the risk factors for reduced bone mineral density (BMD) among postmenopausal women.

Material and methods: Two hundred and fifty-three postmenopausal women were included to the study. The study group consisted of 85 women with osteoporosis (mean age: 59.9 years) and 168 with osteopenia (mean age: 57.8 years). Patients were assigned to groups according to their BMD measured in the lumbar spine, hip and femoral neck by dual X-ray absorptiometry. Bone formation was assessed by measuring serum osteocalcin and bone resorption by measuring serum C-terminal type I $\alpha$-collagen chain telopeptide.

Results: Multiple regression analysis for lumbar spine showed association of age $(p=0.001)$, parental history of fracture $(p=0.05)$, use of hormone replacement therapy $(p=0.034)$, bisphosphonates therapy $(p<0.001)$, calcium and vitamin $\mathrm{D}$ supplements therapy $(p=0.001)$, oestradiol level $(p=0.007)$ and body mass index $(p<0.001)$. Multiple regression analysis for femoral neck and hip total showed association of age $(p=0.001)$, parental history of fracture $(p=0.049)$, use of bisphosphonates $(p<0.03))$ use of calcium and vitamin D supplements $(p=0.039)$, oestradiol level $(p=0.047)$. All the variables together explain $40.4 \%$ of variance in BMD for the lumbar spine and $25.6 \%$ of variance in BMD for femoral neck and hip total.

Conclusions: The present study demonstrated correlations between the variables and BMD, which are known and widely described in the literature. Osteoporosis and osteopenia in Polish subjects appear to be associated with several known risk factors that are well described in the literature.
\end{abstract}

Key words: bone mineral density, postmenopausal women, osteoporosis, osteopenia, multifactorial analysis.

\section{Introduction}

Loss of bone mineral density (BMD) is related to hormonal imbalance, ageing, environmental factors, life style and genetic predisposition. The above causes account for $50-80 \%$ of individual variability in bone mass. Loss of bone mass in women occurs predominantly in the postmenopausal period due to disturbances in the balance between bone resorption by osteoclasts and bone formation by osteoblasts, which lead to reduction in BMD [1]. Loss of BMD in women consists of two stages. It starts after the menopause with an exponential decrease in BMD. This rapid process 
is oestrogen-dependent and lasts approximately 510 years. Subsequently, it is followed by a constant stage that is age-related. The sudden oestrogendependent loss of bone mass after the menopause accounts for $50 \%$ of the total loss in the thoracic and lumbar spine and it is responsible for fractures of the cancellous bone such as compression fractures of vertebral bodies. The age-related loss of bone mass causes thinning of bone trabeculae and loss of bone tissue in the cortical layer. As a result of this process, the cortex becomes porous, which increases the susceptibility to fractures of the femoral neck. The rate of BMD loss may be assessed using biochemical markers of bone remodelling. The markers may illustrate the enzymatic activity specific for osteogenic cells and cells responsible for bone resorption or components of cell matrix released to the blood during bone formation or resorption [2].

The study aimed to determine which sociodemographic and clinical parameters represent risk factors for reduced BMD among postmenopausal women using multifactorial analysis.

\section{Material and methods}

\section{Material}

The study included 253 postmenopausal women recruited from outpatients in the Menopause and Osteoporosis Outpatient Clinic in Poznan between $1^{\text {st }}$ August 2007 and $31^{\text {st }}$ July 2008. In line with the definition of the World Health Organization (WHO) [3], subjects were classified as osteoporotic if their T-score was 2.5 or more standard deviations (SD) below the mean of young normal (T-score $<-2.5$ ), and osteopenic if the lowest of these values was between $<-1.0$ and $>2.5$ SD (T-score $<-1.0$ and $>-2.5 \mathrm{SD}$ ) in at least one of the measurement areas (lumbar spine and hip total). In our study, patients were assigned to two groups according to their BMD measured in the lumbar spine and femoral neck (T-score). The study group consisted of 85 women with osteoporosis (mean age: 59.9 years; $\mathrm{SD}=5.2$ ) and 168 women with osteopenia (mean age: 57.8 years; $S D=4.8$ ).

An inclusion criterion was age between 50 and 70 years. Subjects with secondary osteoporosis, metabolic bone disease, malignant bone metastasis, hypogonadal states, osteogenesis imperfecta and those treated with glucocorticoids were excluded. Endocrine, gastrointestinal, rheumatological and haematological disorders were also among the exclusion criteria.

We obtained written consent of the patients for their participation in the study.

The study was approved by the Ethical Review Committee at the Poznan University of Medical Sciences.

\section{Measurements}

Information on sociodemographic and clinical parameters was collected during interviews with the patients. The patients were asked about their age, age at menopause, marital status, education, work status, living situation, previous non-vertebral fractures, vertebral deformities, parental history of fracture, smoking and drinking alcohol, use of hormone replacement therapy (HRT), use of bisphosphonates, calcium and vitamin D supplements.

Weight and height were measured at the time of bone densitometry assessments. The body mass index (BMI) was calculated as body weight/height ${ }^{2}$ $\left(\mathrm{kg} / \mathrm{m}^{2}\right)$. Body height and weight were measured in indoor clothes without shoes.

Bone mineral density in the lumbar spine $\left(L_{1}-L_{4}\right)$ and hip total (femoral neck) was measured by dual energy X-ray absorptiometry (assessed using a LUNAR DPX device). The women were examined in a horizontal position for lumbar spine and femoral neck. The DEXA method involves a very low radiation dose similar to that of natural background radiation ( $7 \mu \mathrm{Sv} /$ day) [4]. Measurements of bone mineral content $(\mathrm{g})$ and area $\left(\mathrm{cm}^{2}\right)$ are provided for each measurement site. The BMD results are expressed as areal density in $\mathrm{g} / \mathrm{cm}^{2}$. The coefficient of variation (CV) is $0.7 \%$ at the lumbar spine and $1.0 \%$ at the hip [5]. The BMD was compared with an appropriate ethnic and gender matched reference database, and was expressed as a standard deviation score (SD) from the mean of either young adult (T-score) or age matched (Z-score) reference groups [5]. The WHO has defined osteopenia as a T-score $<-1.0$ but $>-2.5$, whilst osteoporosis is defined as a $\mathrm{T}$ score of -2.5 or lower [3].

\section{Vertebral morphometry}

Vertebral fractures in the $L_{1}-L_{4}$ section were evaluated using the DXA method of vertebral fracture assessment (VFA) according to Genant criteria. Vertebral deformity was identified when anterior, middle, or posterior height loss was more than $20 \%$. Mild fractures were defined as $20-25 \%$ height loss. Moderate and severe wedge, biconcave or compression deformities were defined as more than $25 \%$ height loss [6]. Vertebral deformities were assessed using a Luna Prodigy Advance device.

Information on sociodemographic and clinical parameters was collected at the same time as BMD measures.

\section{Biochemistry and markers of bone formation and resorption}

Venous blood samples were collected from postmenopausal women between 8 a.m. and 10 a.m. on a day convenient for them. The subjects had been fasting. Serum specimens were stored at $-20^{\circ} \mathrm{C}$ 
before being analysed. Serum levels of calcium, phosphate and alkaline phosphatase were measured by standard methods. At the same time, blood was collected to determine concentrations of follicle-stimulating hormone (FSH), oestradiol and bone turnover markers.

The concentration of FSH was determined using the Elecsys FSH, while the level of oestradiol was measured employing the Elecsys Kit.

Bone formation was assessed by measurement of the serum level osteocalcin (OC) (BGP - Bone Gla Protein) in the Elecsys N-MID Osteocalcin ${ }^{\circledR}$ CalSet.

Bone resorption was determined by measurement of the serum level of C-terminal type I $\alpha$-collagen chain telopeptide (CTX) using the B-Cross Laps ${ }^{\circledR}$ RP Elecsys Kit.

Biochemistry and markers of bone formation and resorption were examined in the Laboratory of the Obstetric and Gynaecological Hospital in Poznan.

\section{Statistical analysis}

Descriptive statistics of all variables are presented as percentage, mean and SD. Comparisons between the groups were assessed by Student's $t$-tests for parametric values or Mann-Whitney $U$ test and $\chi^{2}$ test for non-parametric values. The $t$-test was employed for statistical comparison of mean levels of biochemistry and markers of bone formation and resorption.

Regression analysis was used to determine factors predicting BMD for lumbar spine, femoral neck and hip total among 253 women with reduced $B M D$, evaluate their significance and assess the proportion of variance explained by them. The regression model analysed the following variables: age, body mass index (BMI), previous fragility fractures, vertebral deformities, parental history of fracture, HRT, use of bisphosphonates, use of calcium and vitamin D supplements, sedentary lifestyle, current smoking, serum FSH, serum oestradiol, serum osteocalcin, serum CTx, serum alkaline phosphatase, serum calcium and serum phosphate.

Factors such as age, BMI, serum FSH, serum oestradiol, serum osteocalcin, serum CTx, serum calcium and serum phosphate were treated as continuous variables. On the other hand, previous fragility fractures, vertebral deformities, parental history of fracture, HRT, use of bisphosphonates, use of calcium and vitamin D supplements, sedentary lifestyle and current smoking were classified as either present or absent. The BMD values for femoral neck and hip total of the participants did not differ significantly. For this reason, the multifactorial analysis was performed jointly for BMD values measured for femoral neck and hip total.

The limit of significance was set at $p<0.05$ for all analyses. All statistical analyses were carried out using SPSS for Windows Version 14.

\section{Results}

Most women from the study groups were married, lived with their families and had a secondary education. A significant difference $(p<0.01)$ was found among the two groups for age and work status (retired). Women from the study groups did not differ significantly regarding marital status, education, living conditions or paid work (Table I).

Table II presents BMD values (T-score and $\mathrm{g} / \mathrm{cm}^{2}$ ) for lumbar spine, femoral neck and hip total. The BMD was evaluated based on the T-score for $L_{1}-L_{4}$ and for femoral neck (hip total): mean T-score was -3.11; -3.1 (-3.0) for osteoporotic women and -1.9; $-1.7(-1.71)$ for the osteopenic group respectively. The BMD $\left(\mathrm{g} / \mathrm{cm}^{2}\right)$ in subjects with osteoporosis was $0.8 ; 0.59$ (0.58), while in osteopenic women it was $0.91 ; 0.7$ (0.71) respectively. The difference was statistically significant for both measurements $(p<0.001)$ (Table II). Table III presents the characteristics of risk factors for reduced BMD.

The BMI in osteoporotic women was lower than in the osteopenic group. The difference was statistically significant $(p<0.001)$.

Over $21 \%$ of osteoporotic and $27 \%$ of osteopenic patients had a history of non-vertebral fractures. None of the subjects sustained a femoral neck fracture. On the other hand, wrist or forearm fractures occurred in almost $12 \%$ of osteoporotic patients and $17 \%$ of osteopenic subjects. Parental history of fracture was reported by $38 \%$ of women with osteoporosis and $41 \%$ of patients with osteopenia. Hip fracture was recorded in 1 parent of osteoporotic women; parents of osteopenic patients did not sustain any hip fractures. On the other hand, wrist or forearm fractures were reported in $28.2 \%$ of parents of osteoporotic subjects and $32.1 \%$ of parents of osteopenic women. Mild vertebral deformities were found in $21.2 \%$ of osteoporotic patients and $8.9 \%$ of the osteopenic group. $14.1 \%$ of patients with osteoporosis and $12.5 \%$ with osteopenia were current cigarette smokers.

Almost $50 \%$ of women in both groups led a sedentary lifestyle. Table IV shows drug treatment in the groups. Osteoporotic and osteopenic patients were taking bone active treatment at the time of the study (HRT, bisphosphonates or calcium supplementation with vitamin D). The HRT was used by $40 \%$ of osteoporotic patients and $47 \%$ of osteopenic women.

Bisphosphonates were administered to $70.6 \%$ of osteoporotic women: $60 \%$ of this group underwent only bisphosphonates therapy $(47.1 \%$ with alendronate administered weekly and $12.9 \%$ with daily doses of alendronate; the time since the first alendronate administration was more than 3 months), while $10.6 \%$ of the women received both bisphosphonates (alendronate administered week- 
Table I. Sociodemographic characteristics of women in groups

\begin{tabular}{|lccc|}
\hline Parameter & $\begin{array}{c}\text { Osteoporotic patients } \\
\text { (T-score } \leq-2.5) n=85\end{array}$ & $\begin{array}{c}\text { Osteopenic patients } \\
(-2.5<\text { T-score } \leq-1.0) n=168\end{array}$ & Value of $p$ \\
\hline Age, mean (SD) [years] & $59.9(5.2)$ & $57.8(4.8)$ & $<0.01$ \\
\hline \begin{tabular}{l} 
Education, $n$ (\%) \\
\hline Basic
\end{tabular} & $2(2.4)$ & $8(4.8)$ & $0.248^{\mathrm{a}}$ \\
\hline Work-related & $10(11.8)$ & $17(10.1)$ & \\
\hline Secondary & $49(57.6)$ & $78(46.4)$ & \\
\hline University level & $24(28.2)$ & $65(38.7)$ & $0.883^{\mathrm{b}}$ \\
\hline \begin{tabular}{l} 
Marital status, $n$ (\%) \\
\hline Married
\end{tabular} & $55(64.7)$ & $105(62.5)$ & $0.839^{\mathrm{b}}$ \\
\hline \begin{tabular}{l} 
Widowed \\
\hline Single
\end{tabular} & $13(15.3)$ & $22(13.1)$ & $0.999^{\mathrm{b}}$ \\
\hline Divorced & $7(8.2)$ & $26(15.5)$ & $0.541^{\mathrm{b}}$ \\
\hline Living situation, $n$ (\%) & $10(11.8)$ & $133(79.2)$ & $0.614^{\mathrm{a}}$ \\
\hline \begin{tabular}{l} 
With family or with another \\
\hline Living alone
\end{tabular} & $64(75.3)$ & $35(20.8)$ & \\
\hline Work status, $n$ (\%) & $21(24.7)$ & $55(32.7)$ & $0.095^{\mathrm{b}}$ \\
\hline $\begin{array}{l}\text { Paid work } \\
\text { Retired }\end{array}$ & $16(18.8)$ & $113(67.3)$ & $<0.01^{\mathrm{b}}$ \\
\hline
\end{tabular}

Student's t-test, ${ }^{a} \chi^{2}$ test, ${ }^{b}$ Mann-Whitney $U$ test

Table II. Bone mineral density measurements

\begin{tabular}{|c|c|c|c|}
\hline Parameter & $\begin{array}{l}\text { Osteoporotic patients } \\
\quad(T-s c o r e \leq-2.5) \\
n=85, \text { Mean (SD) }\end{array}$ & $\begin{array}{c}\text { Osteopenic patients } \\
(-2.5<\text { T-score } \leq-1.0) \\
n=168, \text { Mean }(\mathrm{SD})\end{array}$ & $\begin{array}{c}t \text { (d.f.), } \\
\text { value of } p\end{array}$ \\
\hline T-score $\mathrm{L}_{1}-\mathrm{L}_{4}$ & $-3.11(0.65)$ & $-1.9(0.53)$ & $13.9(196),<0.001$ \\
\hline Bone mineral density (BMD) $\mathrm{L}_{1}-\mathrm{L}_{4}\left[\mathrm{~g} / \mathrm{cm}^{2}\right]$ & $0.8(0.08)$ & $0.91(0.13)$ & $6.6(196),<0.001$ \\
\hline T-score femoral neck & $-3.1(0.44)$ & $-1.7(0.49)$ & $13.9(196),<0.001$ \\
\hline BMD femoral neck $\left[\mathrm{g} / \mathrm{cm}^{2}\right]$ & $0.59(0.06)$ & $0.7(0.11)$ & $6.6(196),<0.001$ \\
\hline T-score hip total & $-3.0(0.42)$ & $-1.71(0.47)$ & 13.9 (196), < 0.001 \\
\hline BMD hip total $\left[\mathrm{g} / \mathrm{cm}^{2}\right]$ & $0.58(0.05)$ & $0.71(0.12)$ & $6.6(196),<0.001$ \\
\hline
\end{tabular}

Significance by t-test for independent samples

ly) and HRT. Moreover, $29.4 \%$ of osteoporotic subjects underwent only HRT. $22.6 \%$ of osteopenic women were treated with bisphosphonates: $3.6 \%$ of this group underwent only bisphosphonates therapy, while $19 \%$ of the women received bisphosphonates and HRT at the same time. Fourty-seven percent of osteopenic patients underwent HRT: $28 \%$ of this group received only HRT, while $19 \%$ of the subjects received both bisphosphonates and HRT.

Over $75 \%$ of women with osteoporosis and almost $50 \%$ of women with osteopenia had been receiving daily doses of $500 \mathrm{mg}$ calcium and $400 \mathrm{IU}$ vitamin D longer than 3 months (Table III).
Table IV shows the mean levels of hormones, bone markers and serum calcium, phosphate and alkaline phosphatase. All the subjects had FSH concentration, oestradiol level, serum calcium, phosphate and alkaline phosphatase within the normal range. Women with osteoporosis and osteopenia who did not take bisphosphonates had poorer serum markers of bone formation and resorption. The $t$-test revealed that OC and CTx levels significantly differed between the osteoporosis women and the osteopenic group. Serum OC for osteoporotic women with bisphosphonates therapy was $12.96 \mathrm{ng} / \mathrm{ml}$, for patients without bisphosphonates 
Table III. Comparison of risk factors across the groups

\begin{tabular}{|c|c|c|c|}
\hline Parameter & $\begin{array}{c}\text { steoporotic patients } \\
\text { (T-score } \leq-2.5) \\
n=85\end{array}$ & $\begin{array}{c}\text { Osteopenic patients } \\
\begin{array}{c}(-2.5<\mathrm{T}-\mathrm{score} \leq-1.0) \\
n=168\end{array}\end{array}$ & Value of $p$ \\
\hline Body mass index (BMI), mean (SD) $\left[\mathrm{kg} / \mathrm{m}^{2}\right]$ & $22.3(3.1)$ & $24.7(4.1)$ & $<0.001$ \\
\hline Age at menopause, mean (SD) [years] & $49.7(4.5)$ & $48.5(5.2)$ & 0.134 \\
\hline \multicolumn{4}{|l|}{ Previous non-vertebral } \\
\hline Fractures, $n(\%)$ & $18(21.2)$ & $46(27.4)$ & $0.236^{a}$ \\
\hline Hip fracture, $n(\%)$ & 0 & 0 & \\
\hline Wrist or forearm, $n(\%)$ & $10(11.8)$ & $29(17.3)$ & \\
\hline Other, $n(\%)$ & $8(9.4)$ & $17(10.1)$ & \\
\hline Mild vertebral deformities, $n$ (\%) & $18(21.2)$ & $15(8.9)$ & $0.041^{b}$ \\
\hline Parental history of fracture, $n(\%)$ & $32(38)$ & $69(41)$ & $0.163^{a}$ \\
\hline Hip fracture, $n(\%)$ & $1(1.2)$ & 0 & \\
\hline Wrist or forearm, $n$ (\%) & $24(28.2)$ & $54(32.1)$ & \\
\hline Other, $n(\%)$ & $7(8.2)$ & $15(8.9)$ & \\
\hline Drinking alcohol, $n$ (\%) & 0 & 0 & \\
\hline Current smoking, $n$ (\%) & $12(14.1)$ & $22(13.0)$ & $0.944^{b}$ \\
\hline Past smoking, $n(\%)$ & $18(21.2)$ & $75(44.6)$ & $0.048^{b}$ \\
\hline Never smoking, $n(\%)$ & $55(64.7)$ & $71(42.4)$ & $0.042^{b}$ \\
\hline Current sedentary, $n$ (\%) & $36(42.3)$ & $91(54.2)$ & $0.142^{\mathrm{a}}$ \\
\hline Current physical activity 1-2 times per week, $n(\%)$ & $47(55.3)$ & 67 (39.9) & \\
\hline Physical activity in the past, $n(\%)$ & $2(2.4)$ & $10(5.9)$ & \\
\hline
\end{tabular}

Student's t-test, ${ }^{a} \chi^{2}$ test, ${ }^{b}$ Mann-Whitney $\cup$ test

Table IV. Drug treatment in the groups

\begin{tabular}{|c|c|c|c|}
\hline Parameter & $\begin{array}{c}\text { Osteoporotic patients } \\
\begin{array}{c}\text { (T-score } \leq-2.5) \\
n=85\end{array}\end{array}$ & $\begin{array}{c}\text { Osteopenic patients } \\
(-2.5<\text { T-score } \leq-1.0) \\
n=168\end{array}$ & Value of $p$ \\
\hline Hormone replacement therapy, $n$ (\%) & $34(40.0)$ & $79(47.0)$ & 0.350 \\
\hline Hormone replacement therapy only, $n(\%)$ & $25(29.4)$ & $47(28.0)$ & \\
\hline $\begin{array}{l}\text { Hormone replacement therapy } \\
\text { and bisphosphonates therapy, } n(\%)\end{array}$ & $9(10.6)$ & $32(19.0)$ & \\
\hline Bisphosphonates therapy, $n$ (\%) & $60(70.6)$ & $38(22.6)$ & 0.024 \\
\hline Bisphosphonates therapy only, $n$ (\%) & $51(60.0)$ & & \\
\hline Weekly alendronate & $40(47.1)$ & $6(3.6)$ & \\
\hline Daily alendronate & $11(12.9)$ & 0 & 0.35 \\
\hline $\begin{array}{l}\text { Bisphosphonates (weekly alendronate) } \\
\text { and hormone replacement therapy, } n \text { (\%) }\end{array}$ & $9(10.6)$ & $32(19.0)$ & \\
\hline Calcium and vitamin D supplements, $n(\%)$ & $64(75.3)$ & $83(49.4)$ & 0.018 \\
\hline
\end{tabular}

therapy it was 16.73; the difference was statistically significant $(p<0.025)$. Serum OC for women with osteopenia with bisphosphonates therapy was $16.41 \mathrm{ng} / \mathrm{ml}$, for women without bisphosphonates therapy it was $19.86 \mathrm{ng} / \mathrm{ml}$; the difference was sta- tistically significant $(p<0.003)$. Serum CTx for osteoporotic women with bisphosphonates therapy was $0.193 \mathrm{ng} / \mathrm{ml}$, for patients without bisphosphonates therapy it was $0.301 \mathrm{ng} / \mathrm{ml}$; the difference was statistically significant $(p<0.003)$. Serum CTx 
Table V. Biochemistry and markers of bone formation and resorption in patients with osteoporosis and osteopenia

\begin{tabular}{|lccc|}
\hline $\begin{array}{l}\text { Biochemistry and markers } \\
\text { (normal range) }\end{array}$ & $\begin{array}{c}\text { Osteoporotic patients } \\
\text { (T-score } \leq-2.5) \\
n=85, \text { Mean (SD) }\end{array}$ & $\begin{array}{c}\text { Osteopenic patients } \\
(-2.5<\text { T-score } \leq-1.0) \\
n=168, \text { Mean (SD) }\end{array}$ & $\mathrm{t}$ (d.f.), value of $p$ \\
\hline Serum FSH [mlU/ml] (25.8-134.8) & $71.71(17.87)$ & $75.38(28.35)$ & $1.25(239), 0.211$ \\
\hline Serum oestradiol [pg/ml] $(<5.0-54.7)$ & $19.41(30.44)$ & $18.01(18.2)$ & $0.46(251), 0.647$ \\
\hline Serum alkaline phosphatase [U/l] (35-104) & $68.77(33.13)$ & $70.18(24.31)$ & $0.38(251), 0.703$ \\
\hline Serum calcium [mmol/l] (2.15-2.55) & $2.4(0.17)$ & $2.57(1.99)$ & $0.76(251), 0.446$ \\
\hline Serum phosphate $[\mathrm{mg} / \mathrm{dl}](2.7-4.5)$ & $3.68(0.49)$ & $3.52(0.55)$ & $2.27(251), 0.024$ \\
\hline Serum osteocalcin $[\mathrm{ng} / \mathrm{ml}]$ & $14.24(7.4)$ & $18.47(7.38)$ & $4.29(251),<0.001$ \\
\hline Serum CTx $[\mathrm{ng} / \mathrm{ml}]$ & $0.23(0.16)$ & $0.33(0.18)$ & $4.78(251),<0.001$ \\
\hline
\end{tabular}

Significance by $t$-test for independent samples

Table VI. Variables associated with BMD in postmenopausal women with reduced bone mineral density evaluated by multiple regression analysis for the lumbar spine

\begin{tabular}{|c|c|c|c|c|c|}
\hline \multirow[t]{2}{*}{ Predictors of BMD } & \multicolumn{2}{|c|}{ Unstandardized coeficient } & \multirow{2}{*}{$\frac{\text { Standardized coeficient }}{\beta}$} & \multirow[t]{2}{*}{ Value of $t$} & \multirow[t]{2}{*}{ Value of $p$} \\
\hline & B & SE & & & \\
\hline Constant & -0.570 & 1.001 & - & -0.570 & 0.569 \\
\hline Age & -0.040 & 0.011 & -0.166 & -3.485 & 0.001 \\
\hline Parental history of fracture & -0.224 & 0.114 & -0.083 & -1.962 & 0.050 \\
\hline Hormone replacement therapy & -0.294 & 0.138 & -0.093 & -2.129 & 0.034 \\
\hline Bisphosphonates therapy & -0.765 & 0.138 & -0.285 & -5.545 & $<0.001$ \\
\hline Calcium and vitamin D supplements & -0.437 & 0.132 & -0.171 & -3.308 & 0.001 \\
\hline Serum oestradiol & 0.005 & 0.002 & 0.136 & 2.737 & 0.007 \\
\hline BMI & 0.069 & 0.014 & 0.222 & 5.055 & $<0.001$ \\
\hline
\end{tabular}

$F(21.362)=14.35, p<0.001$, adjusted $R^{2}=40.4 \%$

for osteopenic women with bisphosphonates therapy was $0.274 \mathrm{ng} / \mathrm{ml}$, for women without bisphosphonates therapy it was $0.373 \mathrm{ng} / \mathrm{ml}$; the difference was statistically significant $(p<0.003)$. The concentrations of the markers of bone formation (OC) and resorption (CTX) in osteoporotic and osteopenic women significantly depended on their use of bisphosphonates. Since the processes of bone formation and resorption are interrelated, the use of antiresorptive medications reduces both bone resorption and formation.

Multiple regression analysis for lumbar spine showed associations with (1) age (reduced BMD with increasing age), (2) parental history of fracture (reduced BMD with parental history of fracture), (3) use of HRT (reduced BMD in women not using hormone replacement therapy), (4) use of bisphosphonates (reduced BMD in women not using bisphosphonates), (5) use of calcium and vitamin D supplements (reduced BMD in women not using calcium and vitamin D supplements), (6) serum oestradiol level and BMI (better BMD with higher serum oestradiol and BMI). All the variables togeth- er explain $40.4 \%$ of variance in BMD. The greatest impact on BMD was observed for bisphosphonates therapy. The second variable in terms of the size of impact was BMI. Variables with the least influence were the use of HRT and parental history of fracture (Table VI). Multiple regression analysis for femoral neck and hip total showed associations with (1) age, (2) parental history of fracture, (3) use of bisphosphonates, (4) use of calcium and vitamin D supplements, (5) serum oestradiol level. All the variables together explain $25.6 \%$ of variance in BMD. Variables related to BMD for both lumbar spine and femoral neck (hip total) included age, parental history of fracture, bisphosphonates therapy, calcium and vitamin D supplements, and serum oestradiol level.

Neither analysis found a correlation between reduced $B M D$ and vertebral deformities, sedentary lifestyle, current smoking, serum osteocalcin, CTx or any of the other biochemical measures.

\section{Discussion}

Our investigation showed that older age, parental history of fracture, low BMI, not using bis- 
Table VII. Variables associated with BMD in postmenopausal women with reduced bone mineral density evaluated by multiple regression analysis for femoral neck and hip total

\begin{tabular}{|lccccc|}
\hline Predictors of BMD & \multicolumn{2}{l}{ Unstandardized coeficient } & Standardized coeficient & Value of $t$ & Value of $p$ \\
\cline { 2 - 5 } & $\mathrm{B}$ & $\mathrm{SE}$ & $\beta$ & & \\
\hline Constant & -0.580 & 1.211 & & -0.471 & 0.549 \\
\hline Age & -0.040 & 0.011 & -0.166 & -3.485 & 0.001 \\
\hline Parental history of fracture & 0.348 & 0.207 & 0.224 & 1.685 & 0.049 \\
\hline Bisphosphonates therapy & -0.665 & 0.238 & -0.245 & -4.345 & $<0.03$ \\
\hline Calcium and vitamin D supplements & -0.514 & 0.244 & -0.338 & -2.106 & 0.039 \\
\hline Serum oestradiol & 0.007 & 0.004 & 0.244 & 1.739 & 0.047 \\
\hline
\end{tabular}

$F(22.68)=1.76, p=0.03$, adjusted $R^{2}=25.6 \%$

phosphonates, not using HRT, not using calcium and vitamin D supplements, and serum oestradiol were risk factors in predicting those with reduced BMD for lumbar spine among postmenopausal women. These factors combined accounted for $40.4 \%$ of the variability in BMD. At the same time, age, parental history of fracture, bisphosphonates therapy, calcium and vitamin D supplements and serum oestradiol were risk factors in predicting those with reduced BMD for femoral neck and hip total. These factors combined accounted for $25.6 \%$ of the variability in BMD. The greatest impact on BMD for lumbar spine was observed for bisphosphonates therapy. Numerous clinical trials have confirmed the beneficial effect of bisphosphonates on BMD [7]. An example may be a study of 8710 patients, which showed that ibandronate treatment enhanced BMD and reduced the incidence of osteoporotic fractures [8]. A different study assessed the effect of teriparatide use in postmenopausal osteoporotic women. The participants were divided into two groups. Group I received $20 \mathrm{mg}$ teriparatide daily for 18 months. The other group was treated with weekly doses of $70 \mathrm{mg}$ alendronate. Moreover, each patient received $1 \mathrm{~g} \mathrm{Ca}$ and $800 \mathrm{IU}$ vitamin D daily. The authors investigated the effect of the therapy on the concentration of bone turnover markers. The conclusion was that teriparatide treatment of osteoporosis is superior to the use of bisphosphonates in protecting bones from fractures and improving the quality of life with regard to the performance of daily work [9]. According to our findings, the second variable in terms of the size of impact on reduced $B M D$ for lumbar spine was BMI. The BMD improves with increasing BMI. The role of low weight and low BMI as risk factors for future occurrence of fractures has been well documented [10]. Population studies showed that low BMI considerably increased the age-specific risk of all fracture types [11]. The fracture risk for the proximal femur was almost twofold higher in subjects with $\mathrm{BMI}$ of $20 \mathrm{~kg} / \mathrm{m}^{2}$ than in those with BMI of $25 \mathrm{~kg} / \mathrm{m}^{2}$.
Variables with the least influence were the use of HRT and parental history of fracture. Reduced $B M D$ is related to age and menopause and associated with oestrogen deficiency. The imbalance between bone resorption by osteoclasts and bone formation by osteoblasts leads to osteopenia and, subsequently, osteoporosis. The present study revealed that women not using HRT had lower BMD. We also found a protective effect of serum oestrogen on BMD of our women. A longitudinal study conducted by Hannan et al. showed that women who used HRT at the time of the study tended to have less bone loss. The protective effect of HRT on bone loss was not observed for all BMD sites in the 32 oestrogen users [12]. A protective effect of oestrogen and serum oestrogen levels on BMD has been reported in cross-sectional and longitudinal studies [13]. Studies of the Framingham cohort showed that women not using HRT had lower BMD than users [14]. The study of Osteoporosis Fractures reported that current users of HRT had $33 \%$ lower rates of bone loss than non-users [15], similarly to the effects in the Hannan et al. study, although a statistically significant difference was noted only for the trochanter [12]. The mechanism of oestrogen effect on bone metabolism is complex and it has not been fully elucidated so far. Research suggests that it may reduce formation and stimulate apoptosis of osteoclasts and exert an additional effect on homeostasis of calcium compounds. Estrogens bind and activate two different oestrogen receptors, $E R \alpha$ and $E R \beta$, which have been found in osteoblasts, osteoclasts and stromal cells of the bone marrow. Numerous reports indicate that estrogens may directly regulate osteoclasts [16]. Study findings also show that these hormones exert an indirect effect on osteoclasts by inhibiting the formation of cytokines, i.e. activators of bone resorption, in osteoblasts and stromal cells of the bone marrow [17]. Parental history of fracture predicts reduced BMD, which may suggest that genetic predisposition influences the rate and degree of BMD loss. Our investigation showed a very weak corre- 
lation between parental history of fracture and reduced BMD. The latest papers describe a statistically significant importance of parental history of hip fracture for the assessment of ten-year probability of fractures $[18,19]$. In our study, parental history of hip fracture was reported for only 1 person and the analysis took into account all non-vertebral parental fractures. The above might be an explanation of the very weak correlation (at the level of $p=0.05$ ) between parental history of fracture and reduced BMD. Studies conducted to date have found that postmenopausal women whose mothers suffered from osteoporosis had lower BMD and were more susceptible to fractures than women in the control group whose mothers were not osteoporotic. Numerous epidemiological studies confirm the importance of a positive family history of mother's osteoporosis as a factor increasing the risk of fractures [20]. The present study did not find a correlation between BMD and vertebral deformity $(p=0.123)$. Only mild vertebral deformities were reported in $21.2 \%$ of osteoporotic subjects and $8.9 \%$ of osteopenic women, and the multifactorial analysis did not reveal a relationship between this variable and BMD of the patients.

Calcium is an important nutritional factor for bone health. A review by Heaney of 139 reports investigating the role of calcium on bone mass concluded that calcium has positive effects on bone mass throughout life [21]. Diet of postmenopausal women very frequently contains insufficient amounts of calcium and vitamin D. Inadequate supply of vitamin $D$ reduces absorption of calcium from the digestive system, at the same time increasing bone turnover and susceptibility to osteoporotic fractures. Supplementation of vitamin D has been demonstrated to decrease the bone loss in the femoral neck of postmenopausal women but its effectiveness in reducing the risk of fractures seems ambiguous. According to Lips et al. [22], vitamin D (400 IU a day) administered without calcium did not reduce the risk of fractures in male and female subjects, while Trivedi et al. [23] found that intake of 100,000 IU vitamin D every four months decreased the incidence of fractures. Similarly, large doses of vitamin D administered as intramuscular injections once a year reduced the number of humeral fractures among Finnish women. Numerous studies indicate that treatment combining calcium and vitamin D has a beneficial effect on BMD of the spine, femoral neck and whole skeletal system in postmenopausal women. Moreover, a therapy combining calcium and vitamin $D$ reduces the incidence of fractures. In the study of Chapuy et al., the proportion of femoral neck fractures and nonvertebral fractures fell from $43 \%$ to $32 \%$ after 18 months of calcium and vitamin D supplementation
[24]. However, the Research Council of the United Kingdom published different findings of a randomized trial using a factor analysis that aimed to assess the effectiveness of therapy consisting in oral administration of vitamin D and calcium every day for secondary prevention of low-trauma fractures in women. The study did not show a significant reduction in incidence of fractures as a result of calcium and vitamin D supplementation [25]. Nevertheless, the majority of trials confirm the therapeutic effect of calcium and vitamin D consisting in prevention of fractures in persons with calcium and vitamin D deficiency [26]. According to the findings of Rabenda et al., the bone quality may be increased during treatment by changing the microstructure of bone in the absence of a change in BMD. Calcium and/or vitamin D may exert an anti-fracture effect through a mechanism independent of bone density [27].

The present study did not consider the time of breast-feeding and the effect of this variable on BMD of post-menopausal women, but it would be worthwhile to quote the findings of research evaluating the effect of breast-feeding duration on BMD of Turkish postmenopausal women. The retrospective study enrolled 587 postmenopausal women, who were divided into 4 groups depending on the time of breast-feeding and into 3 groups based on their DEXA results. The authors found a correlation between the time of breast-feeding and the BMD score for femur and spine. However, the findings do not reveal a relationship between duration of breast-feeding and BMD of patients [28].

Markers of bone turnover represent a more specific and sensitive measure of the process than conventional tools used to date. They assess the current bone turnover, just as BMD provides information on the status of the skeletal system. The markers reflect early changes in the bone metabolism, which help clinicians not only diagnose osteoporosis but also monitor antiresorptive therapy. The multifactorial regression analysis in our study did not indicate the level of the bone turnover markers as a predictor of BMD. Most studies have demonstrated that biochemical markers of bone formation and resorption have been used to predict bone loss and response to treatment of osteoporosis with bisphosphonates and HRT in postmenopausal women [29]. The results of the study by Sypniewska et al. demonstrate a relative imbalance between bone formation and resorption associated with fragility fracture in elderly women with low vitamin D status. Additionally, the authors suggest that compensatory elevation of serum osteoprotegerin, particularly with reduced bone formation, is insufficient to limit bone loss leading to fracture [30]. 
The major limitations of our study are as follows. First, a follow-up study has not been conducted e.g. after a year. Second, the assessment included a limited number of biochemical parameters and bone turnover markers. Third, the effect of double-action medications was not evaluated. The last limitation was due to the fact that at the time of the study only antiresorptives were used in the patients and not double-action agents.

In conclusion, the present study demonstrated correlations between the variables and BMD, which are known and widely described in the literature. Older age, parental history of fracture, low BMI, not using bisphosphonates, not using HRT, not using calcium and vitamin D supplements and serum oestradiol appear to be the main predictors of reduced BMD among postmenopausal women in our investigation.

Osteoporosis and osteopenia in Polish subjects appear to be associated with several known risk factors that are well described in the literature.

\section{Acknowledgments}

Supported by grant from State Committee for Scientific Research in Poland (ref. N404 134 32/4030).

\section{References}

1. Riggs BL, Khosla S, Melton U. A unitary model for involutional osteoporosis: estrogen deficiency causes both types I and II osteoporosis in post-menopausal women and osteoporosis in post-menopausal women and contributes to bone 1055 in aging men. J Bone Miner Res 1998; 13: 763-73.

2. Johnston CC Jr, Slemenda CW. Changes in skeletal tissue during the aging process. Nutr Rev 1992; 50: 385-7.

3. Kanis JA. Assessment of fracture risk and its application to screening for postmenopausal osteoporosis: synopsis of a WHO report. WHO Study Group. Osteoporos Int 1994; 4: 368-81.

4. Blake GM, Naeem M, Boutros M. Comparison of effective dose to children and adults from dual X-ray absorptiometry examinations. Bone 2006; 38: 935-42.

5. Kelly TL Sp, von Stetton E. Performance evaluation of a multi-detector DXA device. J Bone Miner Res 1991; 6 Suppl 1: S168.

6. Genant HK, Wu CY, Yan Kuijk. Vertebral fracture assessment using a semiquantitative technique. J Bone Miner Res 1993; 8: 1137-48.

7. Saag KG, Geusens P. Progress in osteoporosis and fracture prevention: focus on postmenopausal women. Arthritis Res Therapy 2009; 11: 251.

8. Sebba Al, Emkeyb RD, Kohlesc JD, Sambrookd PN. Ibandronate dose response is associated with increases in bone mineral density and reductions in clinical fractures: results of a meta-analysis. Bone 2009; 4: 423-7.

9. Panico A, Lupolo GA, Marciello F, et al. Teriparatide vs. alendronate as a treatment for osteoporosis: changes in biochemical markers of bone turnover, BMD and quality of life. Med Sci Monit 2011; CR442-448.
10. Joakimsen RM, Fonnebo V, Magnus JH, Tollan A, Sogaard AJ. The Tromso study: body height, body mass index and fractures. Osteoporos Int 1998; 8: 436-42.

11. De Laet C, Kanis JA, Oden A, et al. Body mass index as a predictor of fracture risk: a meta-analysis. Osteoporos Int 2005; 16: 1330-8.

12. Hannan MT, Felson DT, Dawson-Hughes B, et al. Risk factors for longitudinal bone loss in elderly men and women: The Framingham Osteoporosis Study. J Bone Miner Res 2000; 15: 710-20.

13. Cauley JA, Gutai JP, Kuller LH, Scott J, Nevitt MC. BlackWhite differences in serum sex hormones and bone mineral density. Am J Epidemiol 1994; 139: 1035-46.

14. Felson DT, Zhang Y, Hannan MT, Kiel DP, Wilson PW, Anderson JJ. The effect of postmenopausal estrogen therapy on bone density in elderly women. N Engl J Med 1993; 29: 1141-6.

15. Fiorelli C, Cori F, Petilli M, et al. Functional estrogen receptors in a human pre-osteoclastic cell line. Proc Natl Acad Sci USA 1995; 92: 2672-6.

16. Pacifici R. Cytokines, estrogen and postmenopausal osteoporosis: the second decade. Endocrinology 1998; 139: 2659-61.

17. Rogers A, Eastell R. Circulating osteoprotegerin and receptor activator for nuclear for NF kappa B ligand (RANKL): clinical utility in metabolic bone disease. J Clin Edocrinol Metab 2005; 90: 151-4.

18. Kanis JA. Johnell O, Oden A, et al. FRAXTM and The Assessment of fracture probability in men and women from the UK. Osteoporos Int 2008; 19: 385-97.

19. Pluskiewicz W, Adamczyk P, Franek E, et al. Ten-year probability of osteoporotic fracture in 2012 Polish women assessed by FRAX and nomogram by Nguyen et al. Conformity between methods and their clinical utility. Bone 2010; 46: 1661-7.

20. Diaz MN, O'Neill TW, Silman AJ. The influence of family history of hip fracture on the risk of vertebral deformity in men and women: The European Vertebral Osteoporosis study. Bone 1997; 20: 145-9.

21. Heaney RP. Calcium, dairy products and osteoporosis. J Am Coll Nutr 2000; 19: 83S-99S.

22. Lips P, Graafmans W, Ooms ME, Bezener PD, Bouter LM. Vitamin $D$ supplementation and fracture incidence in elderly persons. A randomized placebo-controlled clinical trial. Ann Intern Med 1996; 124: 400-6.

23. Trivedi DP, Doli R, Khaw KT. Effect of four monthly oral vitamin D3 (cholecalciferol) supplementation on fractures and mortality in men and women living in the community: randomized double blind controlled trial. Br Med J 2003; 326: 469-72.

24. Chapuy MC, Arlot MF, Duboeuf F. Vitamin D3 and calcium to prevent hip fractures in the elderly women. $N$ Engl J Med 1992; 327: 1637-42.

25. Grant AM, Avenell A, Campbell MK; RECORD Trial Group. Oral vitamin D3 and calcium for secondary prevention of low-trauma fractures in elderly people (Randomised Evaluation of Calcium OR vitamin D, RECORD): a randomized placebo-controlled trial. Lancet 2005; 365: 1621-8.

26. Porthouse J, Cockayne S, King C, et al. Randomised controlled trial of calcium and supplementation with cholecalciferol (vitamin C3) for prevention of fractures in primary care. Br Med J 2005; 330: 1003.

27. Rabenda V, Bruyere O, Reginster JY. Relationship between bone mineral density changes and risk of fractures among patients receiving calcium with or without vitamin D 
supplementation: a meta-regression. Osteoporos Int 2011;

22: 893-901.

28. Yazici S, Korkmaz U, Erkan M, et al. The effect of breastfeeding duration on bone mineral density in postmenopausal Turkish women: a population-based study. Arch Med Sci 2011; 7: 486-92.

29. Garnero P, Shih WJ, Gineyts E, Karpf DB, Delmas PD. Comparison of new biochemical markers of bone turnover in late postmenopausal osteoporotic women in response to alendronate treatment. J Clin Endocrinol Metab 1994; 79: 1693-700

30. Sypniewska G, Sobańska I, Pater A, et al. Does serum osteoprotegerin level relate to fragility fracture in elderly women with low vitamin D status? Med Sci Monit 2010; 16: CR96-101. 